\title{
The impact of internet use on health outcomes in China: A longitudinal study using a three-wave nationwide survey
}

\author{
Takashi Oshio ( $\square$ oshio@ier.hit-u.ac.jp) \\ Hitotsubashi University \\ Xinxin Ma \\ Hosei University \\ Sho Komatsu \\ The university of Tokyo
}

\section{Research Article}

Keywords: China, Dynamic lagged variable regression model, Health outcomes, Internet use

Posted Date: February 17th, 2022

DOI: https://doi.org/10.21203/rs.3.rs-1341839/v1

License: (c) (i) This work is licensed under a Creative Commons Attribution 4.0 International License. Read Full License 


\section{Abstract}

Background: Previous studies have examined the impact of internet use on health in China but have not addressed the reverse causality problem nor analyzed the health status in detail. In this study, we conducted a longitudinal analysis to investigate the causal association between internet use and health status in China to address these problems.

Methods: Using three-wave longitudinal data from the China Family Panel Studies conducted in 2014, 2016, and 2018, we adopted dynamic regression models with lagged internet use variables to examine the association between internet use and five types of health outcomes.

Results: Internet use was positively associated with health outcomes (self-rated health, mental health, and outpatients), and these effects differed by gender, age, and urban/rural region groups.

Conclusions: The results provided rich evidence of the positive effect of internet use on health outcomes in China. Thus, digital economic policies are expected to improve individuals' health status.

\section{Background}

With the progress of information and communication technology (ICT) since the 1970s, internet usage has expanded worldwide, both in developed and developing countries (OECD, 2018). According to data from the China Network Internet Information Center, the number of internet users in China reached 904 million in April 2020 [1], and China has become the country with the largest number of internet users worldwide. Correspondingly, an increasing number of studies have examined the impact of internet use on society-including employment [2-4], income [5, 6], happiness or life satisfaction [7-10], and health status [11-18]-in many countries including China.

In general, internet use may affect an individual's health in both positive and negative ways. For positive effects, (i) internet use may reduce healthcare costs such as travel costs, which may increase the efficiency of healthcare [14]; (ii) internet use may deal with the problem of medical care information asymmetry and reduce the medical care information search cost, which may encourage an individual to learn more knowledge on healthcare to improve their health outcomes [15]; (iii) internet use may increase connections with others and increase social capital and social participation, and it has been reported that both may improve health $[19,20]$. Internet use also has negative effects on health; (iv) it is argued that problematic use may affect sleep and health [11]; finally, (v) internet use may reduce face-to-face communication and crowd out several dimensions of social capital [21], which may lead to feeling alone [22] and increasing the probability of developing a mental health disorder [23]. Thus, the overall effect of internet use on health should be evaluated based on empirical studies. In the current study, we examine the association between internet use and five types of health indicators using three-wave longitudinal data from the China Family Panel Studies conducted in 2014, 2016, and 2018.

This study is expected to make three contributions to the related literature. First, based on three-wave longitudinal survey data from the China Family Panel Studies (CFPS), it addressed statistical issues such as the initial value effect (i.e., the effect of a variable's initial value on its current value) and reverse causality-problems that have remained largely unsolved in previous studies [14-18]. Second, unlike previous studies that concentrated on one type of health status (most of them are self-rated health [SRH]), this study constructed a set of indicators of health outcomes including SRH, mental health, chronic disease, outpatient, and inpatient, which provide rich evidence on the issue. Third, although some studies have reported that the effect of internet use differs by age and urban/rural area group [15, 16], no study has analyzed these differences by gender. This study compared the differences in internet use effects on health by males and females for the first time as well as the differences between age and urban/rural area groups.

\section{Methods}

\section{Study sample}

We used data obtained from the CFPS, which was a nationwide longitudinal survey conducted by Peking University in representative regions of China in 2014, 2016, and 2018. The CFPS was designed to collect individual, family, and community-level longitudinal data in contemporary China. The sample for the 2010 CFPS baseline survey through a multi-stage probability was drawn with implicit stratification. In the 2010 baseline survey, the CFPS successfully interviewed approximately 15,000 families and almost 30,000 individuals within these families, with an approximate response rate of $79 \%$. The respondents were tracked through annual follow-up surveys. The CFPS covered 25 provinces and municipalities in 2010 and 31 provinces in the current survey. Only the latest three waves $(2014,2016$, and 2018) of the CFPS included a survey item on internet usage and were used in this study. The CFPS contains rich individual-and household- 
level information, such as a set of indices on health, demographic characteristics, family structure, household income, house ownership, health behavior, and enrollment in social insurance, which were used in this study. The samples of the CFPS for 2014, 2016, and 2018 were $37,147,36,892$, and 37,354 , respectively. This study focused on individuals aged 16 years or older in the baseline survey, who were committed to at least one of two follow-up surveys. After excluding respondents who were missing key variables used in the statistical analysis, the total number of individuals whose data were used in this study was 60,077 ( 20,024 from 2014, 20,026 from 2016 , and 20,027 from 2018). The sample used in the regression differed slightly depending on the model.

\section{Variables}

The key independent variables were five indices of health outcomes: (i) self-rated health (SRH), (ii) mental health including total mental health disorder $(\mathrm{TMH})$, I find nothing exciting $(\mathrm{MH} 1)$, I feel nervous (MH2), I cannot concentrate on things (MH3), I feel depressed (MH4), I find it difficult to do anything (MH5), and I feel that I cannot continue with my life (MH6); (iii) chronic disease; (iv) outpatient; and (v) inpatient-all of which are binary variables. We constructed the binary variable of $\mathrm{SRH}$ as $1=$ excellent or good and $0=$ otherwise. As for $\mathrm{TMH}$ and $\mathrm{MH1}-6$, we categorized the answers to the question "How often do you feel hopeful about the future?" into each day $=5$, often = 4 , half of days $=3$, sometimes $=2$, rarely or never $=1$. We constructed the binary variables of MH1-6, taking the value 1 when the values of MH1- 6 were equal to 4 or 5 and 0 otherwise. The total score of MH1-6 ranged from 1 to 30 , and we constructed the binary variable of TMH as $1=$ score is more than 15, and $0=$ otherwise. TMH and MH1-6 were part of the original questionnaire in the CFPS and were used for the first time in this study; a high value indicates a higher probability of developing a mental health disorder. We constructed a binary variable of disease by allocating 1 to those who answered that they had one or more diseases diagnosed by doctors and 0 otherwise. We also constructed a binary variable of outpatients or inpatients by allocating 1 to those who answered that they had outpatient or inpatient experiences in the survey year and 0 otherwise. Higher values indicate poor health status for all indices of health outcomes.

The key independent variable was the internet usage dummy variable. Based on the question item "Did you use the internet in the past year?" we scored internet usage as 1 for "used the internet" and 0 for "did not use the internet."

As covariates, we considered the following variables, all of which are likely to have affected the health outcomes and were available from the CFPS: (1) demographic factors including age, sex, years of education, ethnicity (han), Communist Party of China member, urban resident; (2) family factors, including having a spouse or not, number of family members; (3) income factor: per capita household income, house ownership; (4) health behavior (smoking, drinking, and weekly exercise); (5) enrollment pension/medical insurance (1 = enrollment, 0 = otherwise); (6) regions (east, central, and west); and (7) survey years (2014, 2016, and 2018).

\section{Analytic strategy}

As the benchmark, we considered the regression model to estimate the association between internet use and health outcomes, along with a set of covariates, $X$ :

$$
H_{i}=a+\beta I N T_{i}+\sum_{n} \delta_{n} X_{n i}+\epsilon_{i}
$$

1

where $i$ and $n$ denote the individual and covariate, and $\varepsilon$ is an error term.

We addressed the initial value problem [24-26]: health at time $t$ might be affected by health at time $t-1$. To deal with this problem, we considered a dynamic model that included health at time $t-1$ as an explanatory variable. We further addressed the reverse causality problem by using the internet use status at time $t-1$ to mitigate the problem by allowing a one-wave (that is, two-year) lag from internet use to health $[27,28]$. Overall, we estimated the following dynamic model using balanced panel data:

$$
H_{i t}=a+\rho H_{i t-1}+\beta I N T_{i t-1}+\sum_{n} \delta_{n} X_{n i t}+u_{i t}
$$

2

where $t$ and $t-1$ denote a combination of survey years (2014 and 2016) or (2016 and 2018), and $u$ is an error term. In the actual regression analysis, we estimated logistic regression models using a set of binary variables of health indices. We estimated these models not only for the entire sample but also for each sex group (male and female), age group (aged 16-24, 25-44, 45-59, and 60 or above), and area group (urban and rural) to examine heterogeneity.

\section{Results}




\section{Descriptive analysis}

Table 1 summarizes the key features of the study samples used in the statistical analysis. In general, the proportion of those who answered "have used the internet in the past year" was 40.4\% in China from 2014 to 2018.

Table 1

Key features of the study sample

\begin{tabular}{|c|c|c|c|c|c|}
\hline & $N$ & $\%$ & & $N$ & $\%$ \\
\hline Internet use & 57897 & $(40.4)$ & Household income (yuan) & 58619 & \\
\hline Demographic factors & & & & $M$ & $(16552.1)$ \\
\hline Gender & & & & $S D$ & $(3503.9)$ \\
\hline Men & 60074 & $(49.6)$ & Health behavior & & \\
\hline Women & 60074 & $(50.4)$ & Smoking & 60075 & $(28.0)$ \\
\hline \multirow[t]{3}{*}{ Age (years) } & 60077 & & Drinking & 60075 & $(15.2)$ \\
\hline & $M$ & $(46.5)$ & Exercise (times) & 60075 & \\
\hline & $S D$ & $(15.2)$ & & $M$ & $(2.2)$ \\
\hline \multirow[t]{3}{*}{ Education (years) } & 56562 & & & $S D$ & $(3.1)$ \\
\hline & $M$ & $(7.7)$ & Social insurance & & \\
\hline & $S D$ & $(4.8)$ & Pension & 59472 & $(56.4)$ \\
\hline Ethnicity(han) & 59054 & $(96.0)$ & Medical insurance & 59567 & $(91.8)$ \\
\hline Party membership & 56564 & $(5.9)$ & Regions & & \\
\hline Urban & 58738 & $(47.5)$ & East & 60077 & $(41.1)$ \\
\hline Family factors & & & Central & 60077 & $(29.7)$ \\
\hline Having a spouse & 60077 & $(89.0)$ & West & 60077 & $(29.2)$ \\
\hline \multirow[t]{4}{*}{ No. of family members } & 59683 & & Survey years & & \\
\hline & $M$ & $(4.3)$ & 2014 & 60077 & $(33.3)$ \\
\hline & $S D$ & $(2.0)$ & 2016 & 60077 & $(33.3)$ \\
\hline & & & 2018 & 60077 & (33.3) \\
\hline
\end{tabular}

Table 2 presents the unadjusted association between internet use in 2016 and health outcomes in 2018, comparing health outcomes between internet users and non-users using the entire sample; high values indicate poor health outcomes. Internet use was positively associated with SRH, TMH, MH3-6, disease, outpatient, and inpatient. It should be noted, however, that the comparisons in this table did not control for covariates and were not adjusted for potential biases related to cross-sectional comparisons. 
Table 2

Unadjusted association between internet use and health outcomes: total sample in 2016 and 2018

\begin{tabular}{|c|c|c|c|c|c|}
\hline & User (2016) & Non-user (2016) & Difference & & $N$ \\
\hline Health outcomes (2018) & (a) & (b) & (a) - (b) & $t$ test & \\
\hline Self-rated health (SRH: 1-5) & 2.756 & 3.247 & -0.491 & $p<0.000$ & 37870 \\
\hline Total mental health (TMH: 1-30) & 8.182 & 8.604 & -0.423 & $p<0.000$ & 37434 \\
\hline Mental health (MH1: 1-5) & 1.435 & 1.381 & 0.053 & $p<0.000$ & 37453 \\
\hline Mental health (MH2: 1-5) & 1.268 & 1.229 & 0.039 & $p<0.000$ & 37460 \\
\hline Mental health (MH3: 1-5) & 1.695 & 1.816 & -0.121 & $p<0.000$ & 37467 \\
\hline Mental health (MH4: 1-5) & 1.101 & 1.163 & -0.062 & $p<0.000$ & 37458 \\
\hline Mental health (MH5: 1-5) & 1.564 & 1.790 & -0.225 & $p<0.000$ & 37454 \\
\hline Mental health (MH6: 1-5) & 1.118 & 1.226 & -0.108 & $p<0.000$ & 37458 \\
\hline Disease $(0-1)$ & 0.104 & 0.211 & -0.107 & $p<0.000$ & 37871 \\
\hline Outpatient $(0-1)$ & 0.149 & 0.275 & -0.127 & $p<0.000$ & 37871 \\
\hline Inpatient (0-1) & 0.072 & 0.148 & -0.076 & $p<0.000$ & 37871 \\
\hline
\end{tabular}

\section{Regression analysis}

The results of the regression models are summarized in Table 3, which reports the odds ratios (ORs) of reporting poor health status, along with $95 \%$ confidence intervals (Cls), in response to internet use. The table shows that internet use had negative and significant $(p<0.05)$ associations with poor SHR (OR: 0.84, 95\% Cl: 0.78,0.91), MH4 (OR: 0.65, 95\% Cl: 0.51,0.83), MH5 (OR: 0.83, 95\% Cl: 0.75,0.92), MH5 (OR: $0.62,95 \% \mathrm{Cl}: 0.49,0.79)$, and inpatient (OR: $0.90,95 \% \mathrm{Cl}: 0.80,1.00)$. 
Table 3

Estimated associations between internet use and health outcomes ${ }^{\text {a }}$

\begin{tabular}{|c|c|c|c|c|c|}
\hline & OR & & $95 \% \mathrm{Cl}$ & & $N$ \\
\hline Self-rated health (SRH) & 0.84 & ** & (0.78, & $0.91)$ & 33238 \\
\hline Total mental health (TMH) & 0.94 & & $(0.84$ & $1.05)$ & 33155 \\
\hline $\mathrm{MH} 1$ & 0.91 & & $(0.79$ & 1.04) & 33204 \\
\hline $\mathrm{MH} 2$ & 1.00 & & $(0.85$ & $1.18)$ & 33228 \\
\hline MH3 & 1.14 & ** & $(1.05$ & 1.24) & 33229 \\
\hline $\mathrm{MH} 4$ & 0.65 & ** & $(0.51$ & $0.83)$ & 33211 \\
\hline MH5 & 0.83 & $\star \star$ & $(0.75$ & 0.92) & 33219 \\
\hline $\mathrm{MH} 6$ & 0.62 & ** & $(0.49$ & $0.79)$ & 33214 \\
\hline Disease $(0-1)$ & 1.04 & & $(0.95$ & $1.15)$ & 33242 \\
\hline Outpatient $(0-1)$ & 0.98 & & $(0.90$ & 1.06) & 33242 \\
\hline Inpatient $(0-1)$ & 0.90 & * & $(0.80$ & $1.00)$ & 33242 \\
\hline
\end{tabular}

Tables 4-6 summarize the results obtained from separate estimations by sex, age, and area group. Table 4 indicates that internet use had significantly negative associations with poor $\mathrm{SRH}$, mental health disorder of $\mathrm{MH} 3$ and $\mathrm{MH} 4$ and modestly negative associations with mental health disorders of TMH and MH6 $(p<0.1)$ for males; moreover, it had significantly negative associations with poor SRH and mental health disorder of MH4-6 for women. In sum, internet use had a positive effect on improving the health status of both males and females, while the effect was modestly greater for females than males.

Table 4

Estimated associations between internet and health outcomes by gender ${ }^{\text {a }}$

\begin{tabular}{|c|c|c|c|c|c|c|c|c|}
\hline & \multicolumn{4}{|c|}{ Males } & \multicolumn{4}{|c|}{ Females } \\
\hline & OR & & $95 \% \mathrm{Cl}$ & & OR & & $95 \% \mathrm{Cl}$ & \\
\hline $\mathrm{SRH}$ & 0.83 & ** & $(0.75$ & $0.93)$ & 0.85 & ** & $(0.76$ & $0.95)$ \\
\hline $\mathrm{TMH}$ & 0.87 & $\dagger$ & $(0.74$ & 1.03) & 0.98 & & (0.85, & 1.14) \\
\hline MH1 & 0.86 & & $(0.69$ & 1.06) & 0.94 & & $(0.78$ & 1.13) \\
\hline $\mathrm{MH} 2$ & 0.98 & & (0.77, & $1.25)$ & 1.01 & & $(0.80$ & 1.27) \\
\hline $\mathrm{MH} 3$ & 1.22 & ** & (1.07, & 1.39) & 1.06 & & (0.95, & 1.19) \\
\hline $\mathrm{MH} 4$ & 0.66 & * & (0.46, & $0.96)$ & 0.65 & * & (0.47, & $0.90)$ \\
\hline MH5 & 0.91 & & $(0.79$ & 1.06) & 0.75 & ** & $(0.65$ & $0.87)$ \\
\hline MH6 & 0.71 & $\dagger$ & (0.50, & $1.00)$ & 0.58 & ** & $(0.42$ & $0.80)$ \\
\hline Disease (0-1) & 1.01 & & (0.88, & 1.16) & 1.06 & & (0.93, & 1.21) \\
\hline Outpatient $(0-1)$ & 0.97 & & (0.85, & 1.09) & 0.99 & & (0.89, & 1.11) \\
\hline Inpatient $(0-1)$ & 0.89 & & $(0.76$ & 1.04) & 0.92 & & $(0.79$ & 1.07) \\
\hline
\end{tabular}


Table 5 compares the association between internet use and health by age group. The most noticeable finding is that the positive effect of internet use on SRH and mental health was significantly smaller for the younger generation (aged 16-24 years) than for middle- and older generations (aged 45-59, and 60 and over), while the positive effect of internet use on outpatients was greater for younger generations (OR: $2.06, p<0.01$ ) than for middle and older generations, which suggests that the negative effect of internet use was significantly greater for younger generations than for other age groups.

Table 5

Estimated associations between Internet use and health outcomes by age group ${ }^{a}$

\begin{tabular}{|c|c|c|c|c|c|c|c|c|c|c|c|c|c|c|c|c|}
\hline & $\begin{array}{l}\text { Aged } \\
16- \\
24\end{array}$ & & & & $\begin{array}{l}\text { Aged } \\
25- \\
44\end{array}$ & & & & $\begin{array}{l}\text { Aged } \\
45- \\
59\end{array}$ & & & & $\begin{array}{l}\text { Aged } \\
60 \text { or } \\
\text { above }\end{array}$ & & & \\
\hline & OR & & $\begin{array}{l}95 \% \\
\mathrm{Cl}\end{array}$ & & OR & & $\begin{array}{l}95 \% \\
\mathrm{Cl}\end{array}$ & & OR & & $\begin{array}{l}95 \% \\
\mathrm{Cl}\end{array}$ & & OR & & $\begin{array}{l}95 \% \\
\mathrm{Cl}\end{array}$ & \\
\hline SRH & 1.15 & & (0.67, & 1.98) & 0.90 & $\dagger$ & (0.79, & 1.02) & 0.84 & $* *$ & (0.74, & 0.95) & 0.67 & $\star \star$ & (0.54, & $0.84)$ \\
\hline $\mathrm{TMH}$ & 1.73 & & (0.84, & 3.59) & 0.87 & & (0.73, & 1.05) & 0.91 & & (0.77, & 1.08) & 0.70 & $\dagger$ & (0.47, & 1.03) \\
\hline $\mathrm{MH} 1$ & 1.07 & & (0.44, & 2.57) & 0.84 & & (0.66, & 1.05) & 0.96 & & (0.77, & 1.18) & 0.68 & & $(0.42$ & 1.10) \\
\hline $\mathrm{MH} 2$ & 1.19 & & (0.47, & 2.97) & 0.91 & & (0.68, & 1.20) & 1.01 & & (0.78, & 1.29) & 0.91 & & (0.50, & 1.64) \\
\hline MH3 & 1.33 & & (0.81, & 2.18) & 1.13 & + & (0.98, & 1.30) & 1.17 & * & (1.03, & 1.34) & 0.77 & $\dagger$ & (0.59, & 1.01) \\
\hline $\mathrm{MH} 4$ & 0.27 & $\dagger$ & (0.06, & 1.15) & 0.58 & $\star \star$ & (0.38, & 0.87) & 0.73 & $\dagger$ & (0.51, & 1.04) & 0.94 & & (0.47, & 1.91) \\
\hline MH5 & 1.62 & & (0.75, & $3.50)$ & 0.86 & $\dagger$ & $(0.72$, & 1.02) & 0.82 & * & (0.70, & 0.97) & 0.72 & * & (0.53, & 0.98) \\
\hline MH6 & 0.71 & & (0.19, & 2.58) & 0.63 & * & (0.43, & 0.92) & 0.61 & $\star \star$ & $(0.42$ & $0.88)$ & 0.49 & & (0.19, & 1.22) \\
\hline $\begin{array}{l}\text { Disease } \\
(0-1)\end{array}$ & 0.96 & & (0.47, & 1.97) & 1.21 & $\dagger$ & (1.01, & 1.46) & 1.02 & & (0.89, & 1.78) & 0.94 & & (0.75, & 1.17) \\
\hline $\begin{array}{l}\text { Outpatient } \\
(0-1)\end{array}$ & 2.06 & ** & (1.17, & 3.59) & 0.98 & & $(0.82$, & 1.12) & 0.96 & & (0.84, & 1.87) & 0.83 & & $(0.65$ & 1.05) \\
\hline $\begin{array}{l}\text { Inpatient } \\
(0-1)\end{array}$ & 0.90 & & (0.49, & 1.65) & 0.88 & & (0.73, & 1.08) & 0.96 & & (0.87, & 1.13) & 0.97 & & (0.75, & 1.24) \\
\hline
\end{tabular}

Note: ${ }^{a}$ Obtained from dynamic logistic models with lagged explanatory variables (controlled for covariates). ${ }^{\star \star} p<0.01,{ }^{*} p<0.05,{ }^{\dagger} p<$ 0.1 . 
Table 6

Estimated associations between internet and health outcomes by urban and rural group ${ }^{\text {a }}$

\begin{tabular}{|c|c|c|c|c|c|c|c|c|}
\hline & \multicolumn{4}{|c|}{ Urban } & \multicolumn{4}{|c|}{ Rural } \\
\hline & OR & & $95 \% \mathrm{Cl}$ & & OR & & $95 \% \mathrm{Cl}$ & \\
\hline SRH & 0.82 & ** & $(0.74$ & $0.91)$ & 0.85 & * & $(0.76$ & $0.96)$ \\
\hline TMH & 0.90 & & (0.77, & $1.05)$ & 0.97 & & $(0.83$ & 1.35) \\
\hline MH1 & 0.86 & & (0.71, & $1.05)$ & 0.94 & & $(0.77$ & 1.15) \\
\hline MH2 & 0.91 & & (0.71, & 1.16) & 1.07 & & $(0.84$ & 1.35) \\
\hline MH3 & 1.11 & $\dagger$ & (0.99, & $1.25)$ & 1.20 & ** & $(1.05$ & 1.37) \\
\hline $\mathrm{MH} 4$ & 0.70 & & $(0.49$ & 1.01) & 0.61 & ** & $(0.43$ & $0.86)$ \\
\hline MH5 & 0.79 & $\star \star$ & $(0.68$ & $0.92)$ & 0.91 & & $(0.79$ & 1.06) \\
\hline MH6 & 0.62 & ** & $(0.44$ & $0.87)$ & 0.61 & ** & $(0.44$ & $0.87)$ \\
\hline Disease $(0-1)$ & 0.99 & & $(0.88$ & $1.24)$ & 1.12 & & $(0.96$ & 1.30) \\
\hline Outpatient $(0-1)$ & 0.89 & * & $(0.80$ & $1.00)$ & 1.09 & & $(0.96$ & $1.24)$ \\
\hline Inpatient $(0-1)$ & 0.95 & & $(0.83$ & 1.10) & 0.83 & * & $(0.67$ & $0.99)$ \\
\hline
\end{tabular}

Table 6 compares the association between the internet and health in urban and rural area groups. The results show that internet use had significantly negative associations with poor SRH for both urban and rural area groups, significantly negative associations with mental health disorders of $\mathrm{MH} 6$ and $\mathrm{MH} 6$, and modestly negative associations with mental health disorders of $\mathrm{MH} 4(p<0.1)$ for the urban group; that it had significantly negative associations with mental health disorders of $\mathrm{MH} 4$ and $\mathrm{MH} 6$ for the rural group; and that it had significantly negative associations with outpatients for the urban group and inpatients for the rural group. In sum, internet use had a positive effect on improving the health status of both urban and rural groups, while this effect differed between urban and rural residents.

\section{Discussion}

We examined how internet use was associated with health in China from 2014 to 2018. Our regression analysis based on three wave longitudinal data and dynamic models with the lagged internet use variable indicated that internet use had significant positive associations with $\mathrm{SRH}$, and these results on SHR were generally in line with the positive results from previous studies in China using the cross-sectional data analysis method [14-17], which did not fully control for statistical biases, and the study based on two wave longitudinal data [18]. Regarding the association between internet use and other health outcomes, which were estimated in this study for the first time, our results showed that internet use may reduce the probability of developing a mental health disorder and becoming an inpatient nationwide.

These findings can contribute to the literature on the issue of association with the internet and health outcomes from multiple perspectives. It is reported that in 2017,792 million people lived with a mental health disorder; the proportion was $10.7 \%$, which is slightly more than one in 10 people worldwide [29]. The World Health Organization (WHO) reported that 54 million people suffered from depression and about 41 million from anxiety disorders in China [29], and the proportion of people with mental health disorder in this country was more than $12 \%$ of that worldwide. With the exception of increasing public health care expenditure on the treatment of mental health disorders, our results suggest that policies promoting the digital economy and expanding internet penetration may contribute to improving mental health status.

Our estimation results indicated that the positive effect of internet use was modestly significant for males than for females, which may be due to the difference in internet access by gender. It is argued that a gender digital gap exists in internet access that arose in developed countries in the early stages of ICT development [31-33]. According to data from the CNNIC, the proportion of female internet users in China was 30\% in 2000 and 48.1\% in 2020 [1], which suggested a gender disparity in internet access in China. Additionally, the gender gap in educational attainment can lead to a gender gap in internet use skills, which may explain the difference in internet effects on health 
outcomes by gender. Based on the data from CFPS, in 2018, the period of schooling of individuals aged 24 and over was 8.17 years for males-longer than that (6.68 years) for females.

The results indicated disparities in internet use effects among age groups. The positive effect of internet use on health outcomes was greater for middle and older generations; this may be because the problem of addictive use (overuse) of the internet is serious in younger generations compared to other age groups as the ability to control internet addiction is weaker for teenagers than for adults [11].

Furthermore, a disparity existed in the effects of internet use among urban and rural residents. The positive effect of internet use on health outcomes was greater for urban residents than for their counterparts. The reasons for this can be explained as follows: first, the internet penetration rate is lower for rural residents than for urban residents as the development of internet infrastructure is lagged in rural areas. According to No. 45 of the Statistical Report on the Development of the Internet in China published by the China Internet Information Center, the number of internet users in China reached 989 million in June 2020, including 680 million urban residents and 309 million rural residents with internet penetration rates of $76.4 \%$ and $52.3 \%$, respectively [1]. Second, the level of educational attainment is higher for urban residents. For example, based on the CFPS, the average period of schooling of individuals aged 24 and over was 8.84 years for urban residents and 5.98 years for rural residents in 2018. It is predicted that well-educated individuals may have a higher ability to use the internet to improve their health outcomes. The internet access/use skill gap between urban and rural residents can expand the disparity of health outcomes between the two, which may cause the problem of a severe socioeconomic status inequality [34].

Based on the results of this study, we can argue that in general, policies promoting the development of the digital economy may improve the nation's health status. To reduce digital division problems, policies for reducing the problematic use of the internet for teenagers, promoting internet infrastructure expansion in rural areas, and reducing the gender and urban-rural gaps in internet access and education attainment should be considered by the Chinese government.

\section{Conclusions}

We conclude that internet use was positively associated with the health outcomes of individuals aged 16 and over in China nationwide, and the positive effects of internet use differed by sex, age, and urban/rural groups based on three-wave longitudinal data from 2014 to 2018.

This study has several limitations. First, although we used dynamic models with lagged internet use variables, we could not identify causation from internet use to health, which should be investigated in a more in-depth analysis. Second, as no policy reform existed for internet use during the period 2014-2018, we could not investigate the policy effect on the association between internet use and health outcomes based on a quasi-experiment method, which has become an issue to be addressed in future research.

Despite these limitations, we believe that the current study, which took full advantage of longitudinal data, provided new insights for understanding the association between internet use and health. We also expect the Chinese experience to provide valuable lessons for other countries that are also looking to improve nations' health outcomes in the digital economy era worldwide.

\section{Abbreviations}

CFPS, China Family Panel Studies; SRH, self-rated health; TMH, total mental health disorder; total mental health disorder (TMH); MH1: I find nothing is exciting; MH2: I feel nervous; MH3: I cannot concentrate on things; MH4: I feel depressed; MH5: I find it difficult to do anything; MH6: I feel that I cannot continue with my life; Cl: confidence interval; WHO: World Health Organization.

\section{Declarations}

\section{Ethics approval and consent to participate}

The dataset used in this study, the China Family Panel Studies (CFPS), is publicly available (http://opendata.pku.edu.cn/en), and the study protocol was approved by the Ethical Review Committee of Peking University, China. Hence, ethical approval was not required for this study. Survey data were obtained from Peking University with official permission; therefore, the current study did not require further ethical approval, and the need for written consent was waived by the committee.

\section{Consent for publication}

Not applicable. 


\section{Availability of data and materials}

The dataset used in this study, the China Family Panel Studies (CFPS), is publicly available (http://opendata.pku.edu.cn/en).

\section{Competing interests}

The authors declare no competing interests.

\section{Funding}

This research was financially supported by the Japan Society for the Promotion of Science (JSPS KAKENHI, Grant Numbers $20 \mathrm{H} 01512$ and 20K01722). The funding body had no role in the design of the study, the collection, analysis, and interpretation of the data or in writing the manuscript.

\section{Authors' contributions}

XM and TO organized this research project and conceptualized and designed the study. XM and SK collected the data. XM performed the formal analyses. XM prepared the initial manuscript, and XM and TO reviewed and edited the manuscript. XM and TO acquired funds. All authors have read and approved the final manuscript.

\section{Acknowledgments}

Not applicable.

\section{References}

1. China network Internet information center (CNNIC). No. 45 of theStatistical Report on the Development of the Internet in China. 2020. China Network Internet Information Center.

2. Alam K, Mamun SAK. Access to broadband Internet and labour force outcomes: A case study of the Western Downs Region, Queensland. Telemat Inform. 2017;34:73-84.

3. Dettling LJ. Broadband in the Labor Market: The Impact of Residential High-Speed Internet on Married Women's Labor Force Participation. ILR Review. 2017;70:451-82

4. Mao Y, Zeng X. Does Internet use promote female employment?Econ Dyn. 2017;6:21-131(in Chinese).

5. Krueger AB. How computers have changed the wage structure: Evidence from microdata, 1984-1989. Q J Econ. 1993;108:33-60.

6. Miller P, Mulvey C. Computer skills and wages. Aust Econ Pap. 1997;36:106-13.

7. Zhou G, Sun P. The effect of Internet usage on Chinese residents' happiness: Evidence from CFPS. Nankai Econ Stud. 2017;3:18-33 (in Chinese).

8. Zhu Z, Leng C. The impact of Internet use on the subjective well-being of residents: Evidence from CSS2013. Econ Rev. 2018:78-90 (in Chinese).

9. Zhou X, Wang X. The influence of internet usage on the life satisfaction of rural elderly-Empirical analysis based on CLASS 2016 data. J Fujian Agric For Univ (Philos Soc Sci). 2020;23:70-8 (in Chinese).

10. Zhao Y. Internet use and the well-being of rural residents in the context of rural revitalization-An empirical study based on CFPS panel data. Jianghan Academic. 2021;40:5-15(in Chinese).

11. Alonzo A, Hussain J. Strangers S, Anderson KK. Interplay between social media use, sleep quality, and mental health in youth: A systematic review.Sleep Med Rev.2020;56:101414.

12. Tavares Al. Self-assessed health among older people in Europe and internet use. Int J Med Inform. 2020;141:104240.

13. Choi M, Park S, Cha S. Relationships of mental health and Internet use in Korean adolescents.Arch Psychiatr Nurs. 2017;31:566-71.

14. Lu J, Wang B. Research on the mechanism of influence of Internet use on self-rated health. J Sun Yat-Sen Univ (Soc Sci Ed). 2020;60:117-27(in Chinese). 
15. Yang K, Her H. The impact of Internet usage on health of residents: A study from the China Labor-Force Dynamic survey 2016. Nankai Econ Stud. 2020;3:182-203.

16. Zhao J, Liu Z. The impact of Internet use on the health of the elderly. Chin J Popul Sci. 2020;5:14-26(in Chinese).

17. Chen L, Li Y. Research on channels of the impact of Internet use on health. Res Financ Econ Issues. 2020;7:86-93.

18. Zhang $\mathrm{H}$, Wang $\mathrm{H}$, Yan $\mathrm{H}$,Wang $\mathrm{X}$. Impact of internet use on mental health among elderly individuals: A difference in difference study based on 2016-2018 CFPS data.Int. J. Environ. Res. Public Health 2022;19(1), 101.

19. Wangberg SC, Andreassen HK, Prokosch HU, Santana SM, Sørensen T, Chronaki CE. Relations between Internet use, socio-economic status (SES), social support and subjective health. Health Promot Int. 2008;23:70-7.

20. Sun K, Zhou J. Understanding the impacts of Internet use on senior Citizens' social participation in China: Evidence from longitudinal panel data. Telemat Inform. 2021;59:101566.

21. Geraci A, Nardotto M, Reggiani T, Sabatini F. Broadband Internet and social capital.J Public Econ. 2022;206:104578.

22. Saadati HM, Mirzaei H, Okhovat B, Khodamoradi F. Association between internet addiction and loneliness across the world: A metaanalysis and systematic review. SSM Popul Health. 2021;16:100948.

23. Shaw LH, Gant LM. In defense of the Internet: The relationship between Internet communication and depression, loneliness, selfesteem, and perceived social support. Cyberpsychol Behav.2002;5:157-71.

24. Contoyannis P, Jones AM, Rice N. The dynamics of health in the British household panel survey. J Appl Econ. 2004;19:473-503.

25. Wooldridge JM. Simple solutions to the initial conditions problem in dynamic, nonlinear panel data models with unobserved heterogeneity. J Appl Econ. 2005;20:39-54.

26. Wooldridge J. Econometric analysis of cross section and panel data. Cambridge: The MIT Press; 2020.

27. Rothman KJ, Poole C. Science and policy making. Am J Public Health. 1985;75:340-341.

28. Green WH. Econometric Analysis. Prentice Hall; 2012.

29. Dattani S, Ritchie H, Roser M. Mental health.Published online at OurWorldlnData. org. https://ourworldindata.org/mental-health[Online Resource] Accessed on February 3, 2022.

30. World organization. Health (WHO).https://www.who.int/china/health-topics/mental-health[Online Resource]. Accessed February 3, 2022.

31. Bimber B. Measuring the gender gap on the Internet.Soc Sci Q. 2020;81:868-76.

32. DiMaggio P, Hargittai E, Neuman WR, Robinson JP.Social implications of the internet. Annu Rev Sociol. 2001;27:307-36.

33. Fatehkia M, Kashyap R, Weber I. Using Facebook ad data to track the global digital gender gap. World Dev. 2018;107:189-209.

34. Ma X. Public medical insurance reform in China. Springer. Nature. 2022. 